\title{
New technologies applied to master education in the time of COVID-19
}

\author{
Chloe Balleste ${ }^{1}$, Alba Coll ${ }^{1}$, Ricard Valero², David Paredes ${ }^{2}$, Fritz Diekmann², Vicens Torregrosa ${ }^{2}$, Jordi Colmenero ${ }^{2}$ \\ ${ }^{1}$ International Cooperation, Donation and Transplantation Institute, Barcelona, Spain \\ ${ }^{2}$ Department of Surgery and Surgical Specializations, University of Barcelona, Barcelona, Spain
}

Background: Since 2004 a master degree in donation and transplantation has been offered by Donation and Transplantation Institute (DTI) Foundation in collaboration with the University of Barcelona. Since 2011, the program had a blended modular structure: Donation, Transplantation, Management, Tissue Banking, and Internship (IS). In 2020, due to COVID-19, it was adapted to be online. The aim is to analyse the impact of the pandemics on grades and student's satisfaction.

Methods: Until 2019, face to face included the IS, theoretical sessions, simulations, cases debate and group exercises. Since 2020, theoretical sessions have been included in the virtual classroom and practical simulations have been replaced by live sessions. Immersive training (IT) has been employed to substitute IS and family approach (FA) workshop. For IS, a virtual reality tour to a simulated tertiary Spanish hospital. In FA experience, students can virtually meet with patient's family and practice their communication skills. In February 2021 only Donation module has been completed, therefore data are organized in two periods, 2011-2019 and 2020, and the grades obtained in the Organ donation module and the students' satisfaction are evaluated.

Results: In 2011-2019, the average grade in Donation was 8.07/10 and in 2020 the score was 8.08/10. In 2011-2019 the Donation module has been evaluated with an average of 9.58/10. In 2020 the evaluation was 9.36/10. Comparative results indicate slight difference in the values, demonstrating stability despite the difficulties by the pandemic.

Conclusions: The inclusion of new technologies has been essential to keep offering high quality international educational programs. Further exploring of technologies may also improve efficiency.

Corresponding author: Chloe Balleste

E-mail: chloe.balleste@dtifoundation.com

\footnotetext{
(C) The Korean Society for Transplantation

This is an Open Access article distributed under the terms of the Creative Commons Attribution Non-Commercial License (http://creativecommons.org/licenses/by-nc/4.0/) which permits unrestricted non-commercial use, distribution, and reproduction in any medium, provided the original work is properly cited.
} 